\title{
Factors Influencing Wastivity in Small Scale Industries: A Case Study of Hubli-Dharwad
}

\author{
Chetan V. Hiremath ${ }^{1 *}$ and Shankargouda C. Patil ${ }^{2}$ \\ 'Kirloskar Institute of Advanced Management Studies, Harihara, Karnataka, India \\ ${ }^{2}$ Rani Chennamma University, Karnataka, Belgaum, Karnataka, India
}

\begin{abstract}
There are many approaches to enhance the overall performance of the production systems. But these approaches are inclined towards intense use of resources and have caused huge pressure on limited resources. Many scholars suggest waste management as an alternative and complimentary approach to tackle this problem. This approach is in nascent stage and lacks standard definitions, practices and tools. The research is taken up in Dharwad District (Karnataka) to know which major factors contribute significantly for waste generation in small scale units and to test whether wastivity can be used to compare the systems to evaluate their performance. The study found that lack of Production Planning and Control contributes maximum toward waste generation followed by Human Resource practices and Inventory Management. Also, it was found that wastivity can be used as a measure to compare production units as it is unit less and is independent of category of production system. There is a further scope to quantify the contribution of each sub systems towards waste generation to develop larger control mechanisms like Total Waste Management System.
\end{abstract}

Keywords: Production System, Production Planning and Control, Human Resource Management, Inventory Management, Wastivity

\section{Introduction}

The contributions of technology to mankind are immense. These include Penicillin and Chemotherapy in the field of medicine, E-Governance for Public Administration and E-commerce for barrier free trade. Similar advancements in production and manufacturing like CAD, CIM, and Cell Manufacturing have made mass customization possible. Similar choices are enjoyed by no human generations on this planet. The number of humans living on this planet today is equivalent to the sum of all the generations lived before. Thanks to Science and technology.

But, the mindless consumption of resources by this huge number of people at a single point of history is straining the nature. Rapid deforestation, flooding, soil erosion, salination have become more frequent. Formation of industrial clusters to take economic advantage has started to add more toxic wastes, harmful chemicals to water streams and air beyond set norms. The disposed solid and hazardous wastes from these setups is impacting the living conditions of the people in and around these areas. The effects are getting transmitted to far off places because of 'Butterfly Effect'.

These dangerous consumption trends of industries are passed on to society or vice versa. Depending on which position one takes which drives what is an 'egg or chicken' debate. However, irrespective of the position taken, one cannot overlook the effects. One such example is Mumbai disaster of 2005, where, impact of natural disaster was compounded by manmade disaster. Huge Consumption of plastics by the city, blocked drainage systems, heavy showers and the full moon created the havoc. Some studies highlight the need to

*Email: hirechetan@gmail.com 
form special task forces to take care of waste to avoid such tragedies ${ }^{1}$ (Egun, 2009).

But, multi disciplinary approaches suggest both social changes and technology up-gradations. As a result, many attempts are being made, at both industry and house hold levels, to avoid excessive consumption of resources. Many new products are on offer for individuals and technological offers are made to industries.

Though many studies are being undertaken with respect to waste management, most of them are from social background and they address waste management by towns or cities or they are from chemical or nuclear establishments. Most of the studies performed focus mainly on pollution and its effects on overall globe or waste generated by cities and their impact on the health of the people. Very few studies are conducted in industrial waste generation. These studies in industrial waste generation are very specific to their respective areas like nuclear reactors; crude oil blocks etc. and cannot be used by other industries. Also few attempts are made to measure and compare waste generation across the industries or systems. This paper attempts to understand the relationships between various factors and their contribution to waste generation and compare the factors generating the waste across the production systems using the concept of wastivity (Mohanty \& Deshmukh, 1999).

\section{Review of Literature}

There are many studies undertaken at both macro and micro levels to reduce the impact of waste and to improve the overall system performance. Following are some of them:

\subsection{Socio-Economic Aspects of Waste Generation at Macro Level}

Urbanization is producing garbage in the cities at such a scale that collection, treatment and disposal of waste has become one of the biggest challenges of the century. Many nations, multinational companies, industries and individuals do not act in the interest of nature but for their own benefit. This phenomenon is causing not only economic losses but also social and health problems (Babanyara, Usman \& Saleh, 2010). Such a behavior is due to any one or all of the following reasons like lack of awareness, lack of enforcing laws or coordination.

Citizens' attitude and awareness helps a lot to overcome this problem ${ }^{4-9}$. Many people across the world are unaware of the ill effects of the waste and its long term impact on the environment. There is a lot of variation in the level of knowledge pertaining to waste management among the managers, government officials who are directly responsible for handling this problem at city and plant levels. Also, there is a need for stringent laws to curb how waste is generated, handled and disposed.

Coordination between stake holders is important for the managerial function and it equally applies to waste management. Coordination between public, private players and stake holders helps in efficient waste management (Obeng, 2009). Many people across the world make their living by scavenging and also by collecting waste and recycling. Inclusion of these people in organized sector can enhance the solid waste management in large cities, but, are not included due to their status, political manipulations or improper accountability on the part of organized players. Scavengers do not participate as, either they are not aware of the opportunities or because they do not trust local authorities. Such a lack of coordination between various sub components and people affects waste management across the industries and sectors Tubtim, Srisantisuk, Chareonsudjai \& Yoshihide, 2008; Baudouin et al., 2010; Sandberg \& Bildsten, 2011; Zia, Devadas \& Shukla, 2008).

The challenges coupled with the administration of wastes in today's civilization are intricate and diverse in nature. For an efficient and systematic management of wastes, the essential aspects and interaction between them must be identified and clearly understood. Thus, there is an immediate need to understand and tackle waste at firm, industry, corporation, regional, national and finally at global level (Nabegu 2010; Ogbonna 2007; Khalil \& Khan 2009). 


\subsection{Technological Aspects of Waste Generation at Micro Level}

System is a concept using which we separate a part from the whole for our study. Such a system has an imaginary boundary separating it from the surroundings. Systems are made up of interconnected components and have peculiar structure, as in case of eco system where many sub systems co exists. Such structures have a well defined behavior in the sense that they process inputs (material, energy, information or data) into outputs. This concept has wide applications in day to day life activities ranging from fitting an $\mathrm{A} / \mathrm{c}$ to a room to managing big cities or complex nuclear reactors.

The systems view looks at how components are interrelated to each other and whether they give synergic effect, both positive and negative. Synergic effect is more relevant in case of social systems than production systems. Most of the studies in operation management use resource management approach and the methods used are very specialized and specific to a setup. Conventionally, efficiency of such system is measured by productivity. Productivity is the ratio of output given by the system to input provided to the system. Productivity of a highly efficient system is very close to one, but it is never equal to one as a part of input is never converted into desired output it goes waste.

Waste is a necessary evil of any system. Waste is any unnecessary input to or any undesirable output from any system. Waste is generated at various levels across the systems be it production system, corporation, power plant or any other system. Mathematically, sum of output and waste cannot exceed input.

$$
\text { Input }=\text { Output }+ \text { Waste }
$$

Many tools, techniques and methods have been developed to make productivity close to one. These approaches aim to maximize/optimize the utilization of the resources (Antony, 2011). Many researchers consider the limitations of present day technology to transform all input into desirable output and are developing alternative approach to improve performance of a system. They focus on waste generated by a system instead of productivity.
Many argue that productivity cannot be used as a measure of performance due to a high degree of difference between systems - like between eco system and manmade systems. For instance, it is difficult to compare two different systems like Air Conditioner and a Corporation. Both use inputs and convert them into outputs but one uses energy as an input and other information. Also, the outputs generated by these two systems vary.

Instead researchers propose to use entropy and wastivity as a measure of performance. Entropy is a measure of randomness of a system and requires abstract calculations, whereas Wastivity is a concept based on the waste generated by the system and is simple to calculate and use. Wastivity is defined as "any resource deployed in the work process which does not create utility for the stakeholders and can be conceived as waste. We can consider the concept of waisitivity as the ratio of waste of all kinds of the total resource inputs. We can further extend concept of 'net wastivity', as the ratio of net of waste minus recycled to total inputs. From these definitions we have established a model linking productivity and the new concept of wastivity ${ }^{2}$, since, wastivity is defined as a ratio between waste generated by the sytem and input given to the system. For all practical reasons wastivity is preferred over entropy as a measure of efficiency (Cardinali, 2001; Mohanty \& Deshmukh 1999, Sharma et al., 1994). The relation between Productivity and Wastivity is derived by dividing both the sides of Eq. 1 by input. This gives Eq. 2,

$$
1=\text { Productivity }+ \text { Wastivity }
$$

Thus for a given system sum of productivity and wastivity is always unity. The productivity of a system can be made close to unity by making wastivity zero.

A systematic approach would suggest means to minimize waste at all stages of conversion from various sources. For a factory or any other operating system producing tangible output, it is observed that material forms a major component of the total product cost hence material wastage is of critical importance at plant level ${ }^{21}$. Efficient use of waste management includes identification of causes of waste generation, better ways for collection, handling and reduction and 
optimal reuse, recycling and effective disposal (Cardinali, 2001; Sushil, 1990; Turner \& Powell 1991; Nabegu, 2010). New technologies are being used to minimize waste. Many have proposed use of IT and IT enabled services in forecasting and controlling waste at various levels (Alhumoud \& Al-Kandari, 2008; Azuka 2009).

Depending on the type, composition and quantity the solutions vary across the industries. The solutions for waste management come from varied fields of knowledge. Scientists, accountants, managers and even city scavengers have proposed many solutions. It is observed that resource management techniques and waste management tools differ in their approach but share the same objective. Thus, they play a complementary role for each other (Hao, Hills \& Huang, 2007; Soliva et al., 2007; Walker, 2008; Shakman, 2009).

Unlike many inter disciplinary solutions, the present study focuses on simple approach to reduce waste by studying the interrelations between various processes of small scale industries. This study attempts to look at the production systems from input driven perspective unlike output driven convention, where focus is more on intense use of resources than extensive use of resources. Though this is complementary to conventional approach, it has many advantages. This waste management as an approach is in its early stages and taxonomy is not fully evolved.

There are very few studies undertaken at a plant level to address the waste management. Even if such studies exist their focus is more on using waste as bi-products, to reuse it as input or to remanufacture (Guide, 2000). Also, their scope does not go beyond input, conversion processes and output and there is a wide gap in this area of research (Junior \& Filho, 2012) as production process interacts continuously with various functions and processes. Hence it can be assumed that even these functions influence the outcome of the processes. Hence, researchers want to know how various factors like production planning and control, human resource planning and inventory management practices are contributing for waste generation. The contributions of above factors are studied by setting the following hypotheses:
$\mathrm{H}_{\mathrm{o} 1}$ : Human Resource does not influence production planning and control.

$\mathrm{H}_{\mathrm{o} 2}$ : Human Resource does not influence Inventory control practices.

$\mathrm{H}_{03}$ : There is no significant role of production planning and control on waste generation.

$\mathrm{H}_{\mathrm{o4}}$ : Human resource does not play significant role in waste generation.

$\mathrm{H}_{05}$ : There is no significant role of Inventory control practices on waste generation.

\section{Need for the Study}

A survey conducted by a joint panel of International Solid waste Association, United Nation's Environment Program and Secretariat of Basel Convention found that all the countries independent of their economic status, produce waste. Though maximum hazardous waste is generated by chemical plants, it is not restricted to this sector alone, agriculture and heavy industries contribute equally. Also, in developing countries like India small scale industries play a dominant role in both development and waste generation. Due to their inherent deficiencies like unskilled workers, obsolete technology etc. they generate up to $20 \%$ of total waste.

\section{Methodology}

\subsection{Rational for Selecting Dharwad District for the Study}

The study focuses on small scale units of Dharwad district as it is a home for many small scale industries from various sectors - from food processing units to valve manufacturing. The district lies in between North Latitude 15 degree 02 minutes to 15 degrees 51 minutes and East Longitude 74 degrees 43 minutes to 75 degrees 35 minutes. The economy of the district is predominantly agriculture in nature with the majority of the soil being fertile and suitable for cultivation of variety of crops. 3,32,619 hectares is the net area sown and of this $1,17,393$ hectares is sown more than once.

There were 33 large/medium scale industries by the end of March 2007, 14,999 registered small scale industies and more than 9,000 artisan, khadi and village industries in the district. The majority of the 
industries that have come in the district are traditional in nature and the trend of setting up of high-tech industries has been a recent phenomenon, especially in Hubli, Dharwad's twin city. Hubli is a major industrial centre for the manufacture of engineering items; more than $50 \%$ of small scale industries in the city are in this category. Industrial valves, Navalgund carpets, Cattle and Poultry Feeds and National flags are the prominent products of the district. Government has started Software Technology Park in Hubli recently. It is also proposed to set up an Incubation Centre in the complex for first generation IT professionals with plug and play facilities at nominal rates. Presently there are 3 medical transcription units and 5 software data processing units in Hubli and Dharwad.

All the small industries (33) listed in government records working in Hubli and Dharwad for more than five years and making some profit are considered for this analysis considering their varied nature. In other words, the study makes use of the census. All the industries under study employ more than 20 but less than 100 workers. The analysis was carried for 30 units only. The industries were classified into two categories: Mechanical and Non Mechanical depending on what they produced. All the units directly involved in fabrication, machining and valve manufacturing were included in Mechanical category and others were treated as Non Mechanical category.

\section{Findings}

Based on focus group interviews and review of secondary sources, more than 29 variables are identified as causes of waste in different categories. Many of the selected variables share linear relationship with other variables causing multi-co-linearity. It is not possible to build a reasonable model with such variables and some of the variables should be removed from the analysis. About 18 variables are excluded as they show significant bi-variate correlation with remaining variables. The correlation matrix generated with remaining 11 variables is an identity matrix, indicating that variables are unrelated. (Bartlett's test of Sphericity Chi sq $=216.247$ at df $55 \mathrm{Sig}=0.000$ ).

The selected 11 variables are sufficient enough to measure the underlying variance (KAISER-MEYER-OLKIN $(\mathrm{KMO})$ sampling adequacy $=0.676)$. This simplifies the problem for further analysis. The latent variance shared by all other variables under consideration is called Communality. This measure is related with Principal Component Analysis (PAC). PAC separates variables into different Factors by first identifying the underlying for each variable. All the variables except 'Non acquaintance with latest technology' have communalities more than 0.5 .

These variables are reduced to three manageable factors by considering Eigen value more than one using SPSS (Ver. 16.00). Further an analysis is made to know whether the contribution of these factors is significant (Figure 1). This analysis is done by forming latent variables from the shortlisted variables using SmartPLS.

\section{Discussion}

The 11 variables are divided into 3 Factors using PAC. The three factors were identified based on Eigen value more than unity (Table 1). Once, the principal components are identified, they are grouped together based on

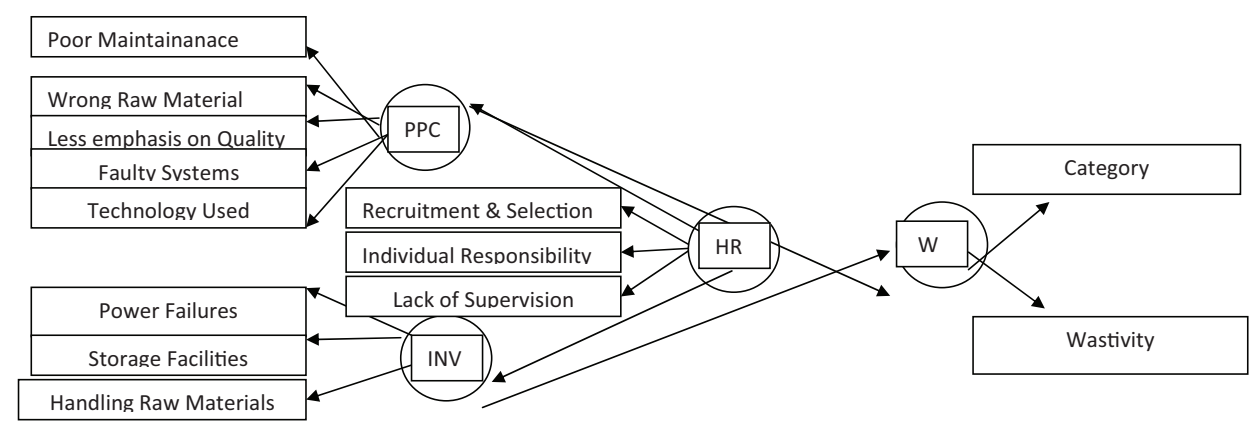

Figure 1. Major factors identified. 
Table 1. Total Variance Explained

\begin{tabular}{ccccccc}
\hline \multirow{2}{*}{ Component } & \multicolumn{3}{c}{ Initial Eigenvalues } & \multicolumn{3}{c}{ Extraction Sums of Squared Loadings } \\
\cline { 2 - 7 } & Total & \% of Variance & Cumulative \% & Total & \% of Variance & Cumulative \% \\
\hline 1 & 5.555 & 50.504 & 50.504 & 5.555 & 50.504 & 50.504 \\
2 & 1.279 & 11.624 & 62.128 & 1.279 & 11.624 & 62.128 \\
3 & 1.048 & 9.526 & 71.654 & 1.048 & 9.526 & 71.654 \\
4 & .957 & 8.696 & 80.350 & & & \\
5 & .754 & 6.852 & 87.202 & & & \\
6 & .557 & 5.060 & 92.262 & & & \\
7 & .348 & 3.167 & 95.429 & & & \\
8 & .228 & 2.069 & 97.499 & & & \\
9 & .141 & 1.279 & 98.778 & & & \\
10 & .078 & .708 & 99.486 & & & \\
11 & .057 & .514 & 100.000 & & & \\
\hline
\end{tabular}

Extraction Method: Principal Component Analysis. Source: SPSS output.

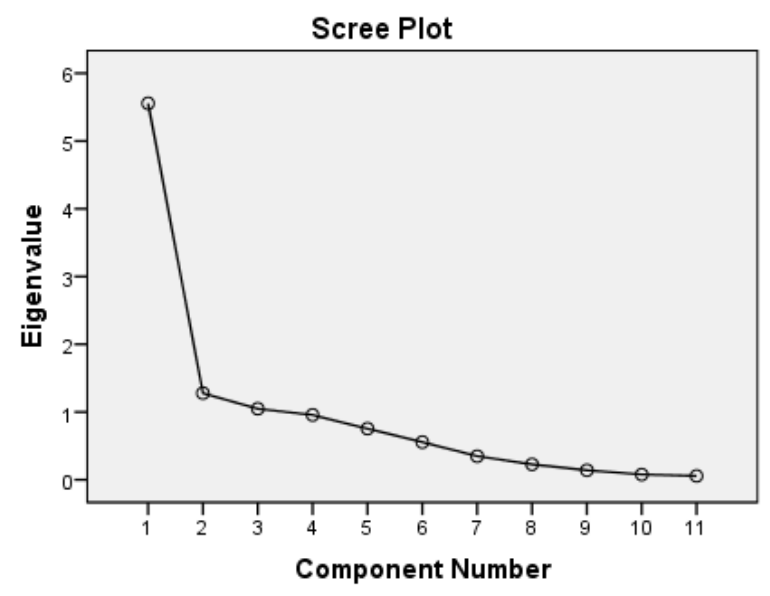

Figure 2. Scree Plot.

the difference between them. To know how each variable is related to individual factors, loadings were calculated. It is seen that 'Poor maintenance' has a highest and 'Poor handling of raw materials' lowest correlation with first factor. Depending on these loadings, individual variables are assigned to separate factors. Later three factors were named - PPC (Production Planning and Control), HR (Human Resource Management) and INV (Inventory Management). The two variables Category and Wastivity are used as dependent variables and were not used to form the above mentioned latent variables.

The first Factor PPC highlights the present level of technology used by the small scale industries in the district
Table 2. Rotated Component Matrix*

\begin{tabular}{lccc}
\hline & \multicolumn{3}{c}{ Component } \\
\cline { 2 - 4 } & 1 & 2 & 3 \\
\hline Poor Maintaince & .833 & & \\
Wrong choice of Raw Material & .825 & & \\
Faulty Systems and Procedures & .794 & & \\
Less emphasis on Quality Control & .752 & & \\
Non Acquaintance with latest technological & .501 & & \\
development & & & \\
Improper Recruitment and lack of Training & & .837 & \\
Inadequate Supervision and Control & & .830 & \\
Lack of Individual Responsibility & & .690 & \\
Frequent Power Failures & & & .862 \\
Inappropriate Storage Facilities & & & .735 \\
Poor Handling of Raw Materials & & & .537 \\
\hline a. Rotation converged in 5 iterations. & & \\
Source: SPSS output * Values less than 0.5 are suppressed. &
\end{tabular}

(Table 2). Also, poor maintenance, wrong choice of raw materials, less emphasis on quality, faulty systems and procedures are other issues included in it. Since most of the small industries in the region are not technically advanced, use of faulty systems and procedures with ill maintained machineries (even some buy used machineries), PPC accounts for up to $50.5 \%$ of variance.

The second factor, HR, explains improper recruitment and training, Lack of supervision and lack of individual responsibility. Grouping of these variables is natural as most of the small scale units in the region 
Table 3. $\quad$ t Statistics for Factors

\begin{tabular}{lccccr}
\hline & Original Sample (0) & Sample Mean (M) & Standard Deviation (STDEV) & Standard Error (STERR) & T Statistics \\
\hline HR $\rightarrow$ INV & 0.550891 & 0.556909 & 0.063329 & 0.063329 & 8.698867 \\
HR $\rightarrow$ PPC & 0.5324 & 0.541043 & 0.042497 & 0.042497 & 12.527872 \\
HR $\rightarrow$ WASTE & 0.679394 & 0.681088 & 0.033024 & 0.033024 & 20.572575 \\
INV $\rightarrow$ WASTE & 0.302599 & 0.308327 & 0.084501 & 0.084501 & 3.581 \\
PPC $\rightarrow$ W WASTE & 0.599218 & 0.593313 & 0.07208 & 0.07208 & 8.313223 \\
\hline
\end{tabular}

Source : Output of SmartPLS.

Table 4. Relationship between Individual Variables and Respective Factors

\begin{tabular}{lccccc}
\hline & Original Sample (0) & Sample Mean (M) & $\begin{array}{l}\text { Standard } \\
\text { Deviation (STDEV) }\end{array}$ & $\begin{array}{l}\text { Standard } \\
\text { Error (STERR) }\end{array}$ & T Statistics \\
\hline CATEGORY <- WASTE & -0.10075 & -0.09501 & 0.125772 & 0.125772 & 0.801053 \\
FAULTY SYSTEMS <- PPC & 0.259052 & 0.258209 & 0.018173 & 0.018173 & 14.255087 \\
FREQUENT POWER FAILURE <- INV & 0.324037 & 0.324524 & 0.042682 & 0.042682 & 7.591926 \\
HANDLING OF RAW MATERIAL <- INV & 0.466949 & 0.465438 & 0.028721 & 0.028721 & 16.25812 \\
IMPROPER STORAGE <- INV & 0.434635 & 0.433745 & 0.040428 & 0.040428 & 10.750906 \\
INDIVIDUAL RESPONSIBILITY <- HR & 0.525523 & 0.531353 & 0.055283 & 0.055283 & 9.506126 \\
LACK OF SUPERVISION <- HR & 0.338739 & 0.335099 & 0.039692 & 0.039692 & 8.534245 \\
LESS EMPHASIS ON QUALITY <- PPC & 0.228914 & 0.228536 & 0.008869 & 0.008869 & 25.811528 \\
POOR MAINTAINANCE <- PPC & 0.228914 & 0.228536 & 0.008869 & 0.008869 & 25.811528 \\
RECRUITMENT \& SELECTION <- HR & 0.28904 & 0.285936 & 0.053679 & 0.053679 & 5.384625 \\
TECHNOLOGY USED <- PPC & 0.243179 & 0.243198 & 0.018112 & 0.018112 & 13.426495 \\
WASTIVITY <- WASTE & 0.988368 & 0.968602 & 0.036709 & 0.036709 & 26.924034 \\
WRONG RAW MATERIAL <- PPC & 0.249019 & 0.2499 & 0.014826 & 0.014826 & 16.796275 \\
\hline
\end{tabular}

Source: Output of SmartPLS.

employ unskilled employees and pay less salary, which accounts for remaining $11.62 \%$ of variance.

Other external variables like frequent power failure, poor handling of raw materials by transporters and inappropriate storage facilitiescaused waste. This isidentified by third factor INV. Only about $9.52 \%$ variance is caused by Inventory Management as industries follow make-to-order policy and amount of material to be handled is less. As a result, inventory management does not cause much waste but frequent power failure does.

The influence of HR is significant on both PPC and INV (Table 3). However, the degree of influence varies. The Production Planning and Control is more affected by HR than Inventory Control. All the factors, Production Planning and Control, Human Resource and Inventory Control practices influence waste generation. The contribution of PPC towards waste generation is the highest, followed by HR and INV.

\section{Conclusion}

All the 11 variables selected have significant contributions to the respective latent variables, except the category to which the industry belongs (Table 4). Also, there is a highest relation between wastivity \& percentage of input, not converted into final product - factor waste indicating that wastivity can be used as a measure of waste.

The present study gives a glimpse of various factors generating waste. It does not quantify their contributions to waste generation as in case of regression analysis, where, weights are assigned to each variable. Also, a more robust model which can explain contribution of each variable would require a larger sample size. Such a model if developed would give better insights into the problem of waste generation and help in developing an integrated approach to tackle waste at various stages of production cycle. 


\section{References}

Akter, N., \& Tränkler, J. (2003). An analysis of possible scenarios of medical waste management in Bangladesh. Management of Environmental Quality: An International Journal, 14, 242-255. doi:10.1108/ 14777830310470459

Alhumoud, J. M., \& Al-Kandari, F. A. (2008). Analysis and overview of industrial solid waste management in Kuwait. Management of Environmental Quality: An International Journal, 19, 520-532.

Antony, J. (2011). Six Sigma vs Lean : Some perspectives from leading academics and practitioners. International Journal of Productivity and Performance Management, 60, 185-190. doi:10.1108/17410401111101494

Aung, M., \& Arias, M. L. (2006). Examining waste management in San Pablo del Lago, Ecuador: a behavioral framework. Management of Environmental Quality: An International Journal, 17, 740-752. doi:10.1108/14777830610702557

Azuka, A. I. (2009). The influx of used electronics into Africa: A perilous trend. Law, Environment, and Development Journal, 5, 92-104.

Babalola, Y. T., Babalola, A. D., \& Okhale, F. O. (2010). Awareness and accessibility of environmental information in Nigeria: Evidence from Delta State. Library Philosophy and Practice (e-journal). Retrieved from http://digitalcommons.unl.edu/libphilprac/460/

Babanyara, Y. Y., Usman, H. A., \& Saleh, U. F. (2010). An overview of the urban property and environmental problems in Nigeria.Journal of Human Ecology, 31(2), 135-143.

Basel Commission (2000). Methodological guide for the undertaking of national inventories of hazardous wastes within the framework of the Basel convention. Retrieved from http://www.unep.fr/.../Chapter\%202.2\%20Methodological\%20Guide

Baudouin, A., Bjerkli, C., Habtemariam, Y., \& Chekole, Z. F. (2010). Between neglect and control: Questioning partnerships and the integration of informal actors in public solid waste management in Addis Ababa, Ethiopia. African Studies Quarterly, 11), 29-42.

Cardinali, R. (2001). Waste management: a missing element in strategic planning. Work Study, 50, 197-201.

Egun, N. K. (2009). Assessment on the level of recycling and waste management in Delta State, Nigeria. Journal of Human Ecology, 28, 77-82.

Guide, R. V. D. (2000). Production planning and control for remanufacturing: industry practice and research needs. Journal of Operations Management, 18, 467-483.
Hao, J. L., Hills, M. J., \& Huang, T. (2007). A simulation model using system dynamic method for construction and demolition waste management in Hong Kong. Construction Innovation: Information, Process, Management, 7, 7-21.

Junior, M. L., \& Filho, M. G. (2012). Production planning and control for remanufacturing: literature review and analysis. Production Planning \& Control, 23, 419-435. doi:10.1080/09537287.2011.561815

Khalil, N., \& Khan, M. (2009). A case of a municipal solid waste management system for a medium-sized Indian city, Aligarh. Management of Environmental Quality: An International Journal, 20, 121-141. doi:10.1108/14777830910939444

Mohanty, R. P., \& Deshmukh, S. G. (1999). Managing green productivity: a case study. Work Study, 48, 165-169.

Nabegu, A. B. (2010). An analysis of muncipal solid waste in Kano Metropolis, Nigeria. Journal of Human Ecology, 31, 111-119.

Obeng, P. A., Donkor, E. A., \& Mensah, A. (2009). Assessment of institutional structures for solid waste management in Kumasi. Management of Environmental Quality: An International Journal, 20, 106-120.

Ogbonna, D. N., Amangbara, G. T., \& Ekere, T. O. (2007). Urban solid waste generation in Port Harcourt metropolis and its implications for waste management. Management of Environmental Quality: An International Journal, $18,71-88$.

Sandberg, E., \& Bildsten, L. (2011). Coordination and waste in industrialised housing. Construction Innovation: Information, Process, Management, 11, 77-91.

Saunders, J., \& Wynn, P. (2004).Attitudes towards waste minimization amongst labor only sub-contractors. Structural Survey, 22, 148-155.

Shakman, A. (2009). Redefining foodservice waste management - Food waste focus [Web log post]. Retrieved from http://blog.leanpath.com/2009/12/new-article-redefining-foodservice-waste-management/

Sharma, H. D., Gupta, S. D., \& Gupta, A. D. (1994). Entropy, quality and wastivity: a unified view of system performance. Kybernetes, 23, 47-54. doi:10.1108/03684929410071187

Soliva, M., Bernat, C., Gil, E., Martínez, X., Pujol, M., Sabaté, J., \& Valero, J. (2007). Education and research related to organic waste management at agricultural engineering schools. International Journal of Sustainability in Higher Education, 8, 224-233. doi:10.1108/14676370710726670

Sood, S., \& Sharma, A. (2009). Knowledge of rural and urban homemakers in Indigenous Resource Management Practices. Journal of Human Ecology, 26, 85-87. 
Sunthornchai, P., Khotbunthou, S., Boujai, P., \& Thamaseananupap, P. (2010). A development of waste management training model. The Social Sciences, 5, 302-304.

Sushil (1990). Waste management: a systems perspective. Industrial Management \& Data Systems, 90, 1-67.

Tubtim, S., Srisantisuk, S., Chareonsudjai, P., \& Yoshihide, S. (2007). Empowerment improvement of the scavenger's identity in Thailand. Journal of Applied Sciences, 7, 883892. doi:10.3923/jas.2007.883.892

Turner, R. K., \& Powell, J. (1991).Towards an integrated waste management strategy. Environmental Management and Health, 2, 6-12. doi:10.1108/09566169110000682

Walker, T. (2008). The applicability of an operations management approach to councils' waste services. International Journal of Productivity and Performance Management, 57, 177-181. doi:10.1108/17410400810857004

Zia, H., Devadas, V., \& Shukla, S. (2008). Assessing informal waste recycling in Kanpur City, India. Management of Environmental Quality: An International Journal, 19, 597-612.

\section{About the Author(s)}

Chetan Virupaxayya Hiremath is working as Senior Lecturer at Kirloskar Institute of Advanced Management Studies. He graduated from K.L.E's Institute of
Engineering and Technology, Belgaum in Mechanical Engineering and a pursued Post graduation from K.L.E's Institute of Management Studies and Research, Hubli. He has completed his M.Phil from Bharathair University in Management. He has published 15 papers in national journals and presented 12 papers at national and international conferences. He has an interest in inter-disciplinary research. and can be contacted at:hirechetan@gmail.com

Dr. S C Patil is basically a technocrat from B V B College of Engineering and Technology, Hubli and has served KCSPLtd, for four years. He pursued higher studies in management from Karnatak University Dharwad and as professor at K L E Society's Institute of Management Studies and Research for twelve years. His doctoral work is on "Quality of Work Life at Small Scale Industries in Dharwad district", with Ph.D. awarded from Shivaji University Kolhapur. He has published around 20 papers in international and national journals and conferences. Has co-authored three books. He has served as Principal KLE Society's College of Business Administration and presently serving as Associate Professor in PG Department of Management, Rani Channamma University, Belgaum. He can be contacted at: patilsc2809@gmail.com. 
